\title{
Use of the endoscopic vacuum therapy technique for the treatment of esophageal fistulas: an integrative review and clinical case series study
}

Wolfram Weber de Souza Amorim 1*, Gabriel Lima de Souza Gonzalez 2, Thiago Nepomuceno de Sabóia Mont'Alverne 1, Francisco Antônio Araújo de Oliveira 1, Tiago César Uchôa Pereira 1, Alessandrino Terceiro de Oliveira 1

${ }^{1}$ Residência Médica em Endoscopia - Serviço de Endoscopia, Hospital Geral de Fortaleza, Ceará, CE, Brazil.

${ }^{2}$ Faculdade de Medicina, Universidade Nilton Lins, Amazônia, MA, Brazil.

* Autor Correspondente: Wolfram Weber de Souza Amorim. R. Ávila Goularte, 900 - Papicu. Cep: 60150-160 Fortaleza, CearálCE, Brasil. Phone: +55 (85) 9 99979-9199. E-mail: weberamorim6@gmail.com.

Research Ethics Committee Approval (if necessary): We declare that the patient approved the study by signing an informed consent form and the study followed the ethical guidelines established by the Declaration of Helsinki.

Received on: Jan 5, 2022. Accepted on: Jan 30, 2022. Available online: Feb 4, 2022.

\section{Abstract}

Esophageal fistula is a rare disease with a mortality rate of up to $31 \%$ of cases and with multifactorial causes. The most common etiologies of esophageal perforation are associated with iatrogenic, foreign body ingestion, as well as cases of lesions of neoplastic origin. Consisting of an innovative therapy with efficiency not yet evaluated in clinical studies, the present study sought to report a series of cases of patients with esophageal fistulas undergoing treatment with endoscopic vacuum therapy (VTE) assisted by the service team of a tertiary public hospital. from the state of Ceará in order to contribute with evidence that reinforces the role of VTE in the closure of esophageal perforations of different etiologies. In addition, in order to contextualize the importance of the cases presented, we carried out an integrative review in order to list the main clinical findings on the use of VTE available in the world scientific literature. There was a need for continuous development of new clinical studies that seek to improve and validate the use of VTE for the safe and effective treatment of esophageal fistulas, emphasizing that treatment with VTE can maximize the therapeutic response, bringing a greater and better clinical patient satisfaction.

Keywords: Fistulas; Endoscopic Vacuum Therapy; Treatment. 


\section{Introduction}

Esophageal perforation or fistula is a rare, potentially fatal problem, with a mortality rate of up to $31 \%$ of cases and with multifactorial causes. The most common etiologies of esophageal perforation are associated with iatrogenic, spontaneous and foreign body ingestion, as well as cases of lesions of neoplastic origin. Esophageal fistula presentation is usually associated with very evident clinical symptoms, such as nausea, vomiting and epigastric pain, requiring a high index of clinical suspicion to result in timely diagnosis and treatment [1-2].

Several therapeutic modalities are available to treat esophageal perforation, including primary surgical repair, surgical resection of the defect, endoscopic stents, and endoscopic suturing. Additionally, as an emerging and promising alternative for endoluminal closure, it is seen that the use of endoscopic endoluminal vacuum therapy (VTE) treats the defect through mechanisms of control of the source of leakage, formation of granulation tissue, stimulating the reperfusion and debridement of necrotic tissue as sponges are removed or replaced [3-4].

Technically, VTE consists of a surgical procedure that uses a polyurethane sponge drain positioned in the esophageal lumen or inside the fistulous cavity with its connection connected to a continuous negative pressure vacuum system. However, it can also be performed using a low-cost modified drainage system, using a nasogastric tube with gauze coated with perforated sterile plastic [5].

Consisting of an innovative therapy with efficiency not yet evaluated in clinical studies, the present study sought to report a series of cases of patients with esophageal fistulas undergoing treatment with endoscopic vacuum therapy assisted by the service team of a tertiary public hospital in the state of Ceará in order to contribute with evidence that reinforces the role of VTE in the closure of esophageal perforations of different etiologies. In addition, in order to contextualize the importance of the cases presented, we carried out an integrative review in order to list the main clinical findings on the use of VTE available in the world scientific literature.

\section{Methodology}

In addition to the clinical description of the case reports, an Integrative Review (IR) study was carried out, restricting theoreticalmethodological, quantitative or qualitative research, which investigated clinical, surgical, epidemiological and therapeutic data of patients, regardless of gender and age, submitted to VTE treatment for the treatment of esophageal fistulas published from 2017 to 2022 (maximum 5 years), regardless of language.

The scientific survey was based on the use of a search filter for 
Use of the endoscopic vacuum therapy technique for the treatment of esophageal fistulas

references related to case reports (Case Reports). Primary studies that did not assess the clinical aspects, and their derivations, of the use of VTE were excluded, such as experimental studies, clinical trials or publication of scientific productions of congress abstracts, academic manuscripts, such as monographs, dissertations and theses, and, finally, technical documents.

For the purposes of IR consolidation, we sought to answer two main questions, namely (1) does the scientific text present clinical data on patients diagnosed with esophageal fistula? (2) does the text consistently discuss the importance of using VTE for clinical reversal of esophageal fistula?. It is noteworthy that the survey of scientific articles, as well as the obtaining of information, was carried out by two professionals, independently.

In a second stage, the establishment of inclusion and exclusion criteria was recommended, always focusing on the research question established at the time of identification of the theme. For this, as for the search strategy, Pubmed was used, which includes MEDLINE, as an informational resource. From this, studies that fit the expressions "endoscopic vacuum therapy" and "esophagus", in their versions in English or Portuguese, were included for later verification of the title, abstract or subject of the manuscript. November 2021 to January 2022.

Studies in which the assessment of VTE therapy was a secondary outcome or an analyzed variable, without being the main focus of the research, were excluded. In the third stage, the identification of pre-selected and selected studies was carried out, based on a careful reading of the titles, abstracts and keywords of all complete publications located by the search strategy used.

Then, the categorization of the selected studies followed, in order to summarize and document the information extracted from the scientific articles found in the previous phases. Finally, the presentation of the review and the synthesis of knowledge followed, favoring the obtaining of information that would allow readers to assess the pertinence of the procedures used in the preparation of the review.

The team performing this research committed to complying with all regulatory guidelines and standards described in Resolution No. 466 of December 12, 2012 and Circular Letter No. 166 of June 12, 2018 of the National Health Council that approves the guidelines and regulatory norms for research involving human beings and for the development of Case Report studies.

\section{Case report}

From the clinical routine of the Endoscopy Service of a public tertiary hospital in the state of Ceará, it was possible to identify a total of 5 patients diagnosed with esophageal fistulas, 
caused by different clinical occurrences, and surgically treated with VTE.

\section{Case 1}

A 71-year-old male patient with a history of dysphagia, episodes of asphyxia and significant weight loss was admitted to the endoscopy service of the Hospital Geral de Fortaleza for diagnostic investigation.

The initial upper digestive endoscopy (EDA) exam showed a lesion in the middle esophagus that compromised the lumen of the organ. Upon biopsy, a clinical diagnosis of Squamous Cell Carcinoma was diagnosed. As a therapeutic abortion, the patient was submitted to Chemotherapy + Radiotherapy sessions with a neoadjuvant proposal. Subsequently, the patient underwent a surgical procedure of Esophagogastrectomy followed by reconstruction with a gastric tube.

On the 17th postoperative day, the patient underwent a new UDE for evaluation of the anastomosis, showing a large fistulous orifice of about $4 \mathrm{~cm}$ in diameter on the posterior wall of the gastric tube that communicated with the adjacent cavity, containing purulent content and necrotic residues (Figure 1).

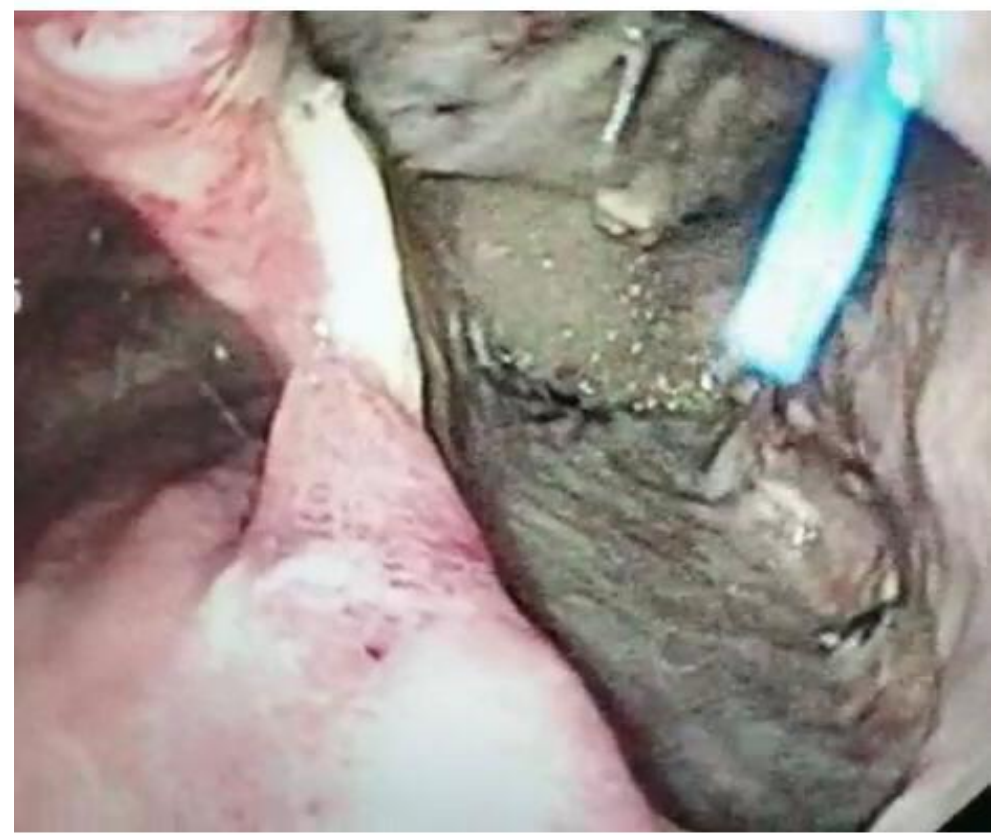

Figure 1: Endoscopic visualization demonstrating the identification of a fistulous orifice with communication with an adjacent cavity, containing purulent content and necrotic residues.

As a therapeutic approach, tube. Endoscopic revision was Endoscopic Vacuum Therapy (EVT) was performed every 5 days to change the performed using a No. 16 nasogastric tube and clean the fistulous cavity with 
washing and removal of necrotic residues (Figure 2A). On the third session (10th postoperative day), the fistulous cavity closed, but with the persistence of a septum between it and the lumen of the gastric tube, which favored the accumulation of infected materials and residues (Figure 2B).
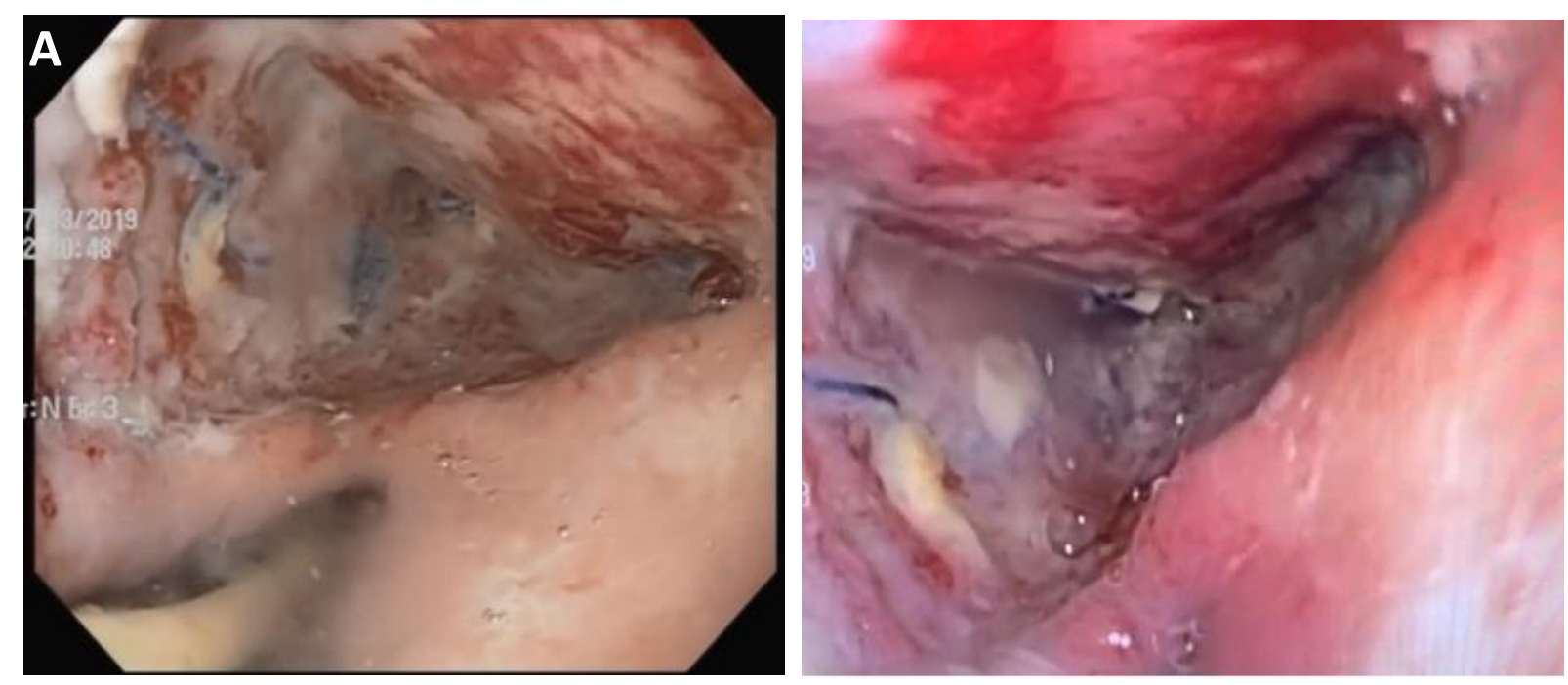

Figure 2: A. Endoscopic visualization demonstrating the identification of a significant improvement in the tissue appearance of the gastric cavity with formation of granulation tissue and fibrin after the 5th day of the EVT procedure. B. Identification of fistula cavity closure without identification of contamination or infection.

\section{Case 2}

A 56-year-old male patient with a history of dysphagia and weight loss, diagnosed with Esophageal Squamous Cell Carcinoma, underwent neoadjuvant radiotherapy and chemotherapy, and subtotal esophagectomy, lymphadenectomy and anastomosis between the cervical esophagus and the gastric tube.

After the surgical procedure, the patient presented a complete
Based on this diagnosis, it was decided to perform an Endoscopic Septotomy with the aid of an endoscopic triangular knife (Triangle Knife), which contributed to the closure of the fistulous cavity and improvement of local contamination. 


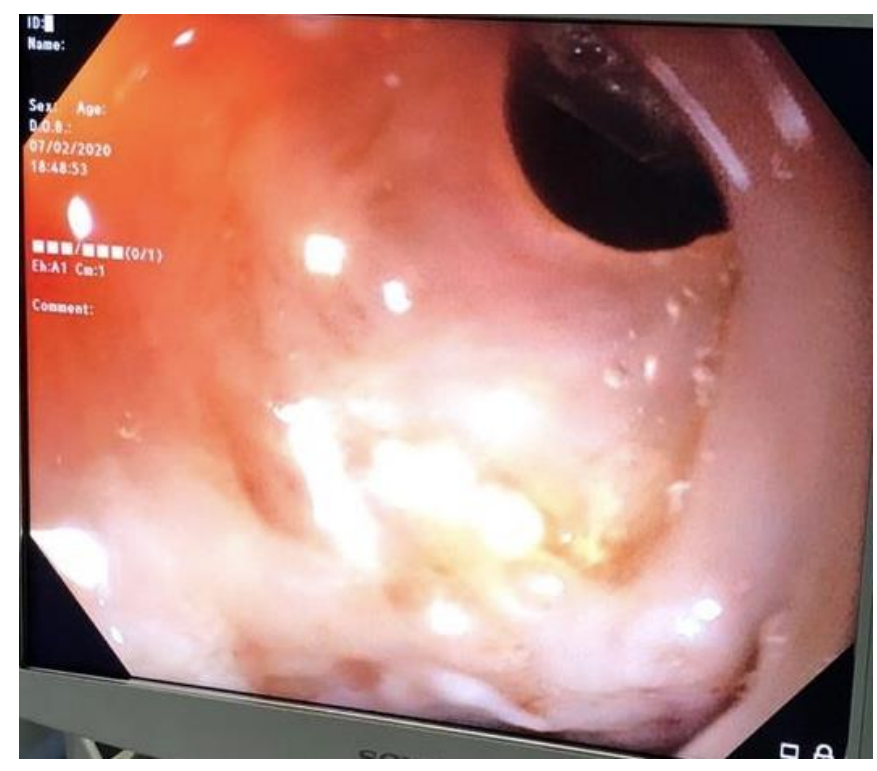

Figure 3: Endoscopic visualization of the presence of an esophageal-bronchial fistula at the level of the esophageal-gastric anastomosis.

It was decided to perform endoscopic vacuum therapy for 15 days, with revision at intervals of 05 and 07 days, obtaining satisfactory results with the closure of the fistula (Figures 4 and
5). The patient still needed to be hospitalized for longer due to complications such as pneumonia and recurrent pleural effusion, improving with clinical treatment.

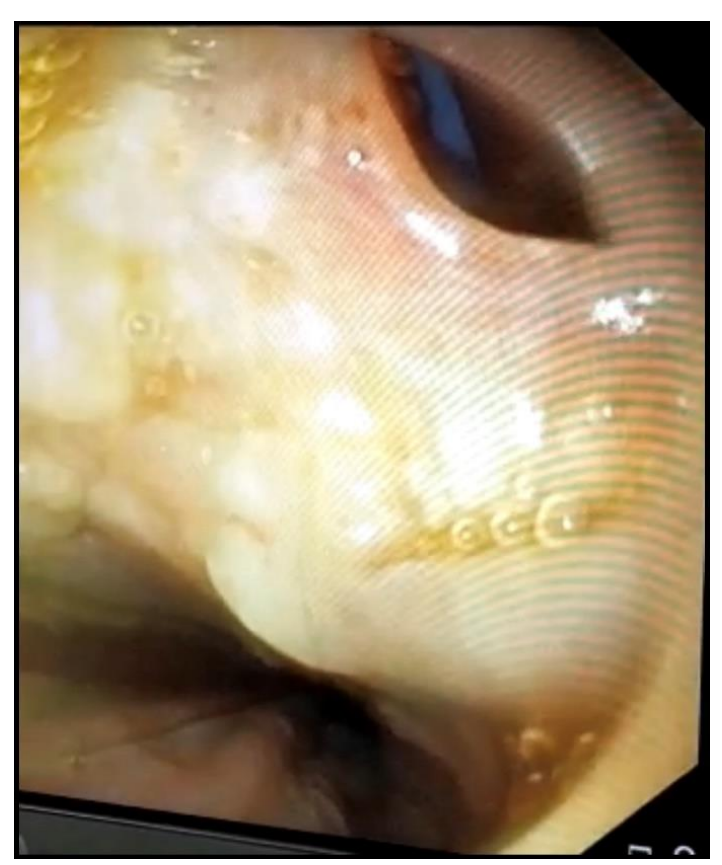

Figure 4: Endoscopic visualization after the 5th postoperative day after performing the EVT procedure. 
Figure 5: Endoscopic visualization after the 12th postoperative day of performing the EVT procedure, with visualization of the total closure of the fistula.

\section{Case 3}

A 43-year-old male patient, orally, food came out through the victim of a firearm projectile in the cervical region, underwent exploratory cervicotomy, showing a lesion of $40-50 \%$ of the trachea in the left posterolateral region at the level of the second tracheal ring. The intraoperative upper digestive endoscopy showed a transfixing lesion in the proximal esophagus (left lateral wall), located $17 \mathrm{~cm}$ from the upper dental arch, associated with friability and hematoma on the anterior and posterior wall.

A Tracheostomy, suture of the esophageal lesion, suture of the trachea and drainage of the esophageal bed with Penrose were performed. On the 14th day, when trying to restart the diet

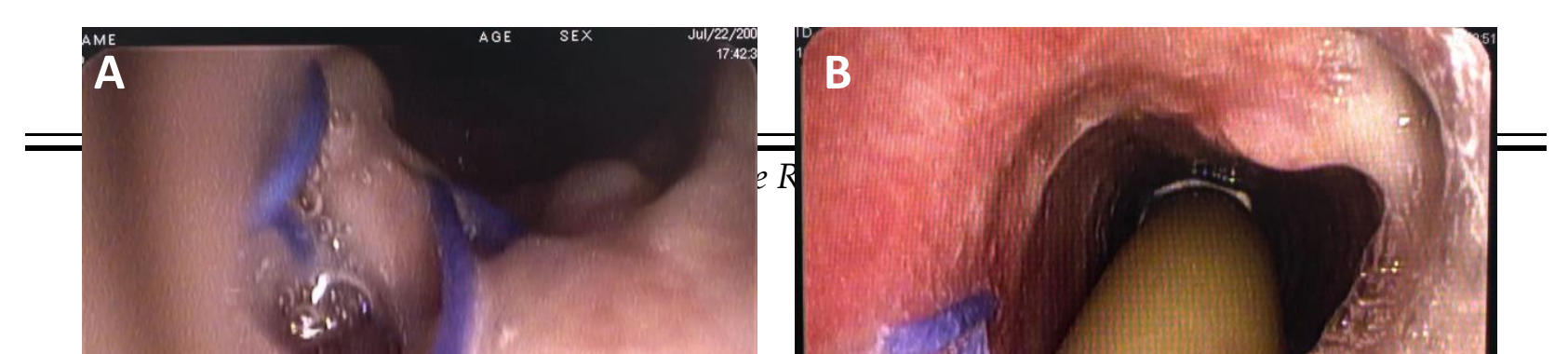


Figure 6: Endoscopic (A) and tracheoscopy (B) visualization of the presence of a fistula in the left anterolateral wall of the proximal esophagus.

The patient underwent of the fistula and tube replacement, and endoscopic vacuum therapy with a No. on the 11th day, closure of the fistula 16 nasogastric tube positioned was evidenced, which was also intraluminally close to the fistula visualized by tracheoscopy (Figures $8 \mathrm{~A}$ (Figure 7). The surgical procedure was and $8 \mathrm{~B}$, respectively). reviewed on the 5th day for evaluation

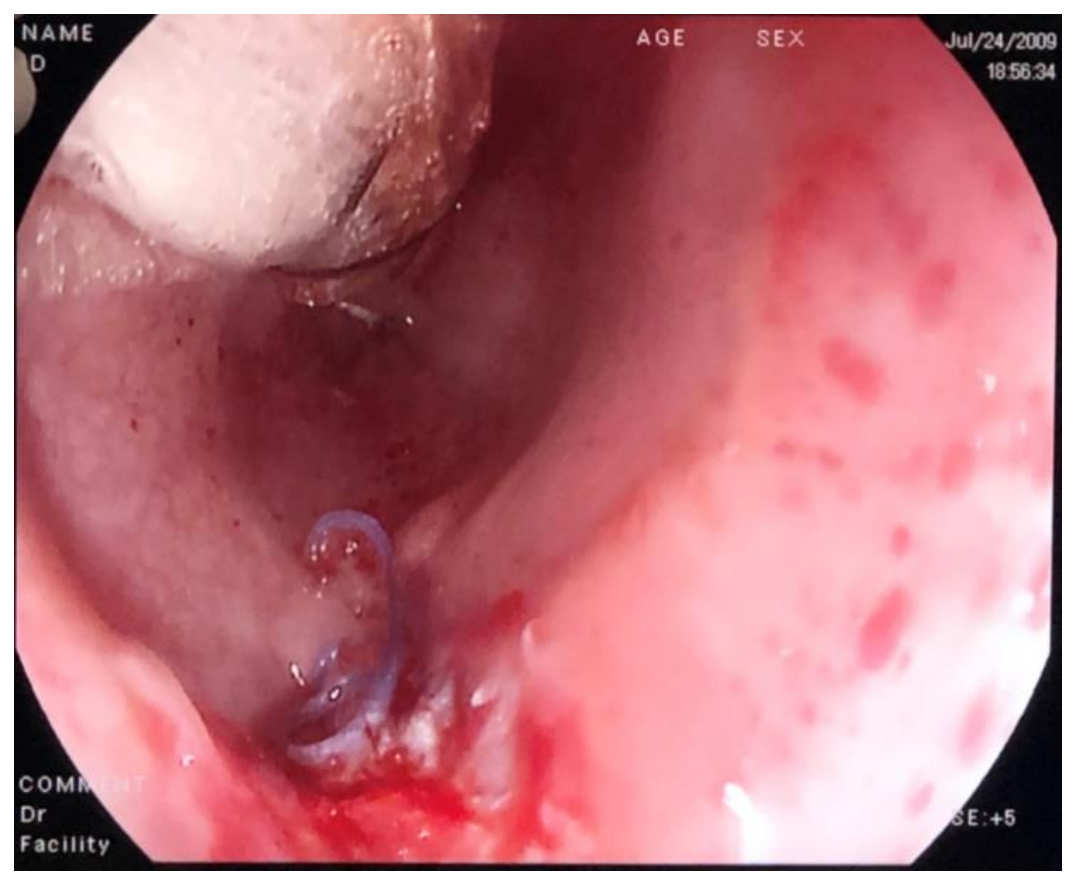

Figure 7: Endoscopic visualization of Vacuum Therapy positioning in an intra-luminal manner. 
Figure 8: Endoscopic view (A) and tracheoscopy view (B) demonstrating the closure of the fistula after the 14 th postoperative day.

\section{Case 4}

A 62-year-old male patient, examination showed parietal thickening hypertensive, ex-smoker, without at the level of the middle/distal evident weight loss, was admitted to the esophagus and the presence of endoscopy service with a complaint of bilaterally sparse non-calcified epigastric and retrosternal pain, "burning" type, with 03 months of clinical evolution.

The patient was referred for upper digestive endoscopy (UGE), which showed an ulcerative-infiltrative lesion measuring $4 \mathrm{~cm}$ in length, friable, bleeding, with areas covered by fibrin, located on the left lateral wall, affecting $50 \%$ of the esophageal circumference, starting at $30 \mathrm{~cm}$ from the upper dental arch.

A biopsy was performed which revealed the diagnosis of Moderately Differentiated Esophageal Squamous Cell Carcinoma. A chest tomography micronodules, of a nonspecific nature.

The CT scan of the abdomen and pelvis showed no significant changes. For the treatment of carcinoma, the patient underwent neoadjuvant chemotherapy and radiotherapy sessions. After neoadjuvant therapy, a new control UDE was performed, which showed remission of the lesion. As a surgical approach, the patient underwent distal esophagectomy without thoracotomy + partial gastrectomy with vagotonia and lymphadenectomy.

On the 5th postoperative day, the patient evolved with increased secretion 
output through the Penrose drain (positioned in the cervicotomy), raising the suspicion of cervical fistula (Figure 9). A new UDE was performed, which showed a wide and patent esophagogastric anastomosis, with the presence of suture threads and areas covered by fibrin located $21 \mathrm{~cm}$ from the upper dental arch. The presence of a fistulous orifice measuring about $07 \mathrm{~mm}$ in diameter was evidenced, with drainage of purulent secretion, and it was possible to visualize the penrose drain inside (Figure 10).

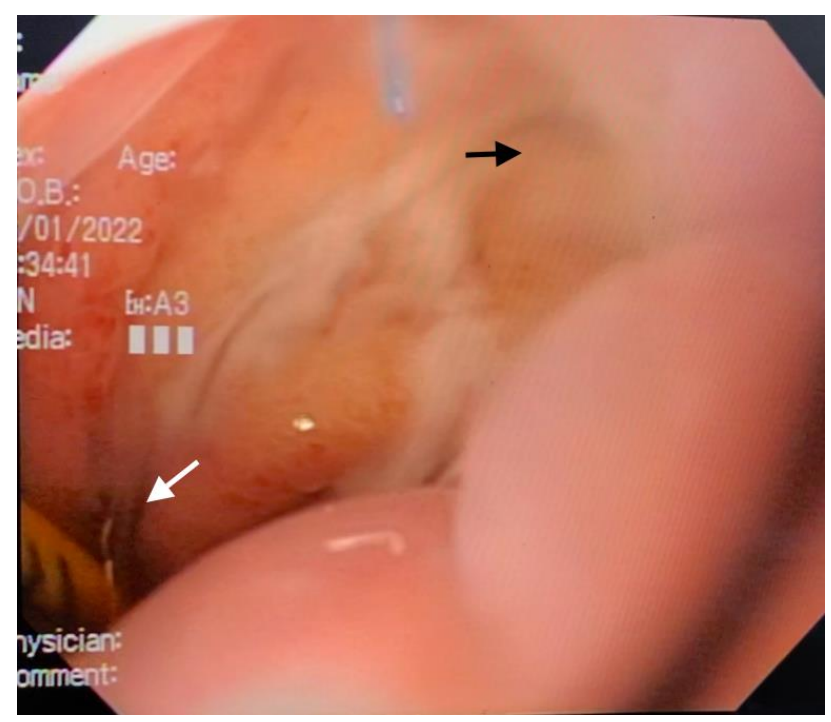

Figure 9: Endoscopic view of the esophagogastric anastomosis. White arrow points to the esophageal lumen. Black arrow points to the fistula with purulent drainage.

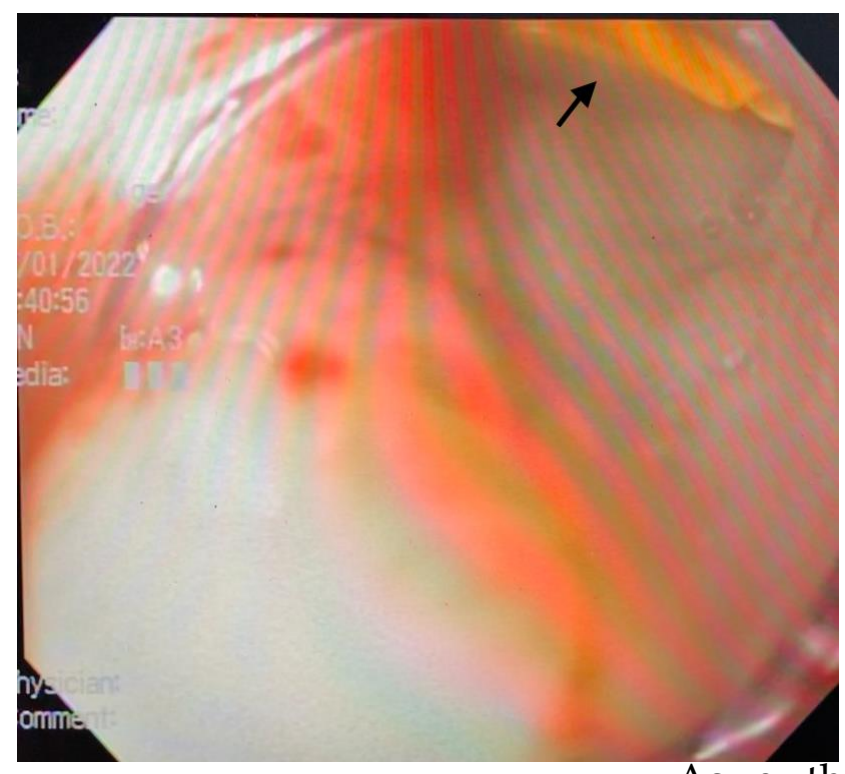

Figure 10: Endoscopic view demonstrating direct views of the therapeutic appropach for for to Penrose drain. fistula consolidation, a No. 16 nasogastric tube was inserted, prepared 
with gauze and perforated plastic, to establish VTE (Figure 11). The patient maintained an enteral and parenteral diet for another 03 days, when weaning started. After 7 days, a significant reduction in penrose drain output was observed. Finally, a new revision UDE showed complete closure of the fistula and the patient was discharged with outpatient follow-up (Figure 12).

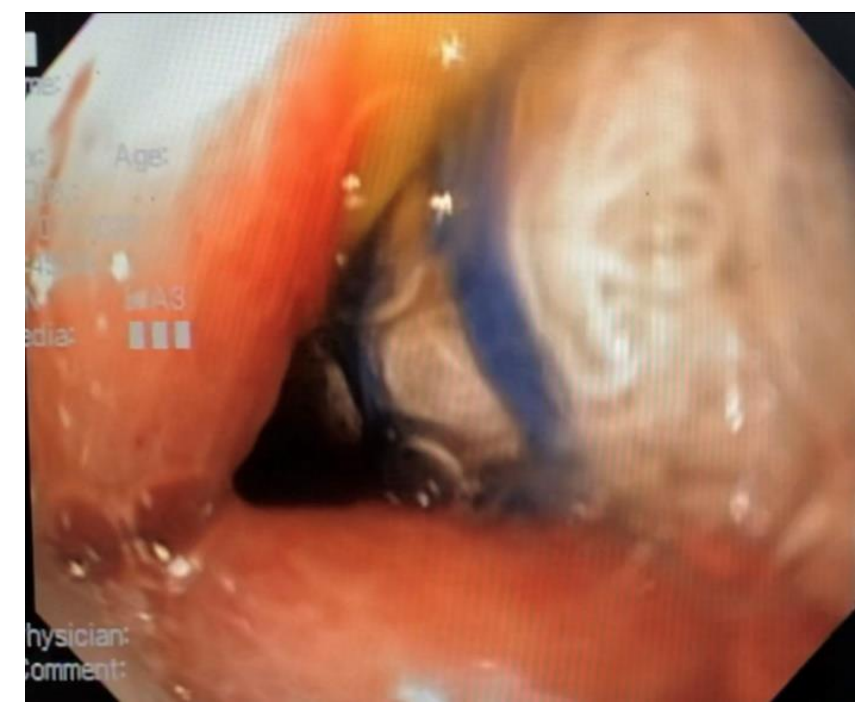

Figure 11: Endoscopic view demonstrating tube placement for vacuum therapy.

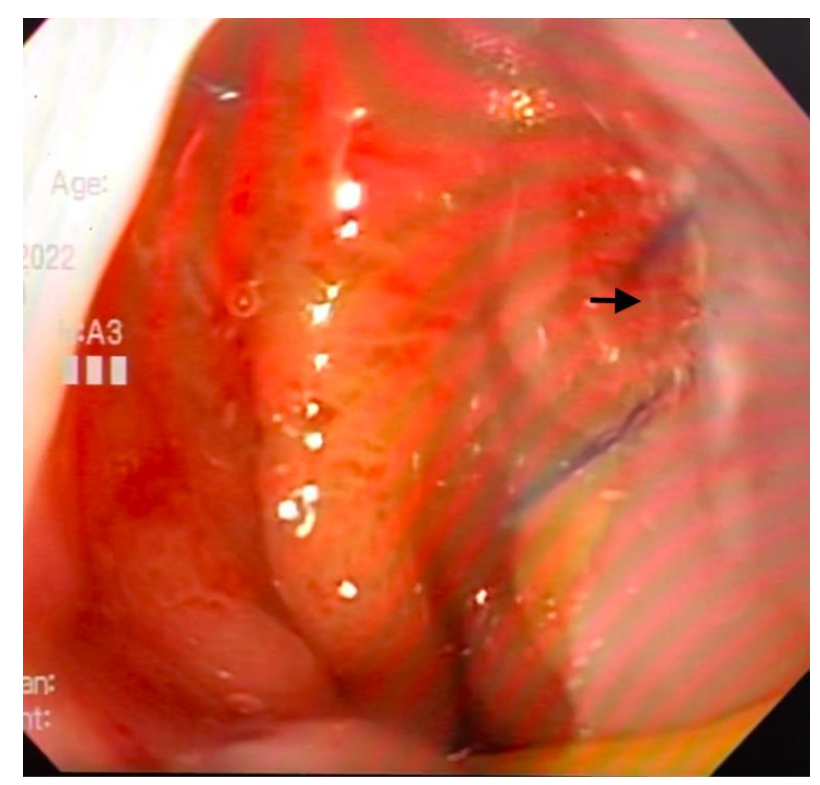

Figure 12: Endoscopic view demonstrating fistula closure 7 days after VTE.

\section{Case 5}


A 63-year-old male patient, complaining of epigastric pain, feeling of postprandial fullness and weight loss with about 5 months of evolution, was assisted by the emergency department with a picture of upper intestinal obstruction and hematemesis. After initial examinations, the diagnosis of advanced gastric neoplasia was disputed.

As surgical therapy, the patient underwent Subtotal Gastrectomy + Gastrojejunoanastomosis to Billroth II. The histopathological examination showed the presence of an advanced stomach adenocarcinoma $\left(\mathrm{T}_{3} \mathrm{~N}_{2} \mathrm{M}_{1}\right)$ - R2 resection. Subsequently, the patient developed a high-output enterocutaneous fistula in the postoperative period, being submitted to a new surgical approach, in which Anastomosis Raffia + Duodenal Stump Raffia + Cavity Cleaning was performed.

On the 5th postoperative day, secretion drainage was maintained through the surgical wound, but in small amounts. An upper digestive endoscopy (EDA) was performed, and a wide and patent gastrojejunal anastomosis was visualized, with the presence of sutures and a fistulous orifice measuring approximately $04 \mathrm{~mm}$ located in the posterior wall (Figures $13 \mathrm{~A}$ and $13 \mathrm{~B})$.
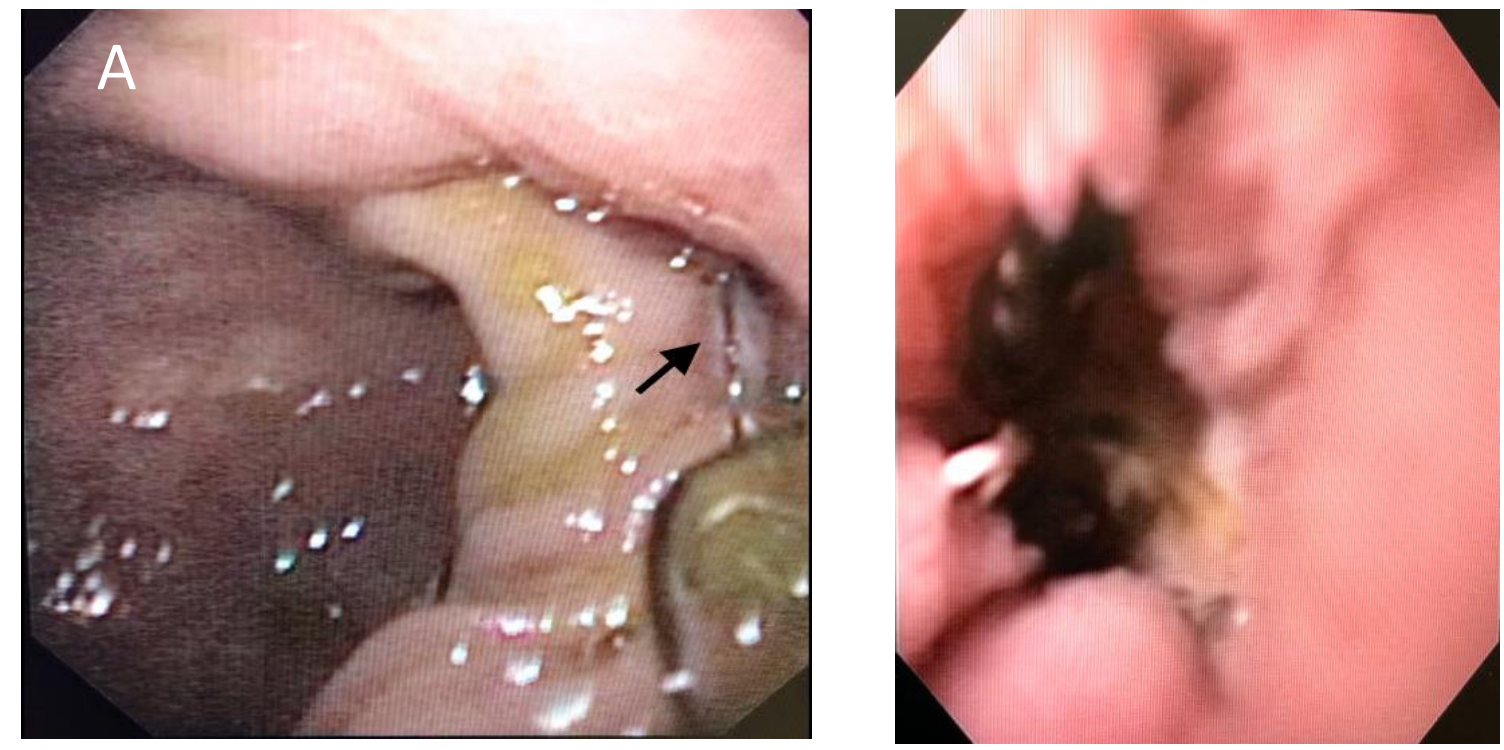

Figure 13: Endoscopic view demonstrating (A) the presence of a fistula at the level of the Gastroenteroanastomosis and (B) the direct view of the fistula. 
The patient underwent EVE therapy using a No. 16 nasogastric tube positioned intraluminally, close to the fistulous orifice. In the endoscopic review after the 7 th day, the fistulous orifice was no longer visible. However, as the patient was still draining a small amount of yellow-green secretion through the surgical wound, we chose to keep the vacuum therapy for another 07 days (Figure 14).

On the 14th day, the operative wound was no longer draining and endoscopy showed closure of the fistula (Figure 15). As a final outcome, the patient was discharged with outpatient follow-up by the surgery and oncology team.

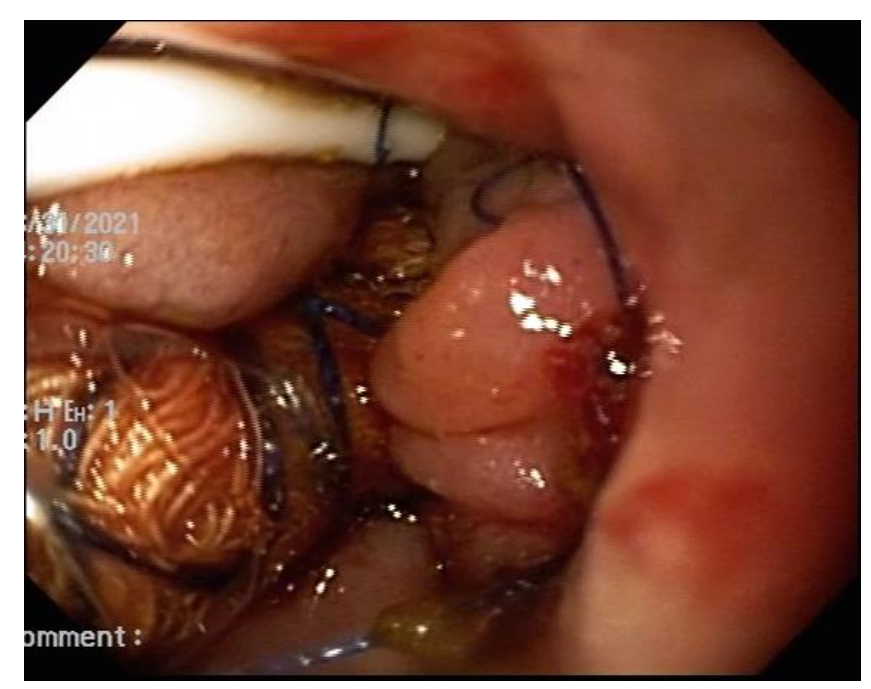

Figure 14: Endoscopic view demonstrating fistula closure in endoscopic review on the 7th day after VTE. Probe positioned at the level of the anastomosis.

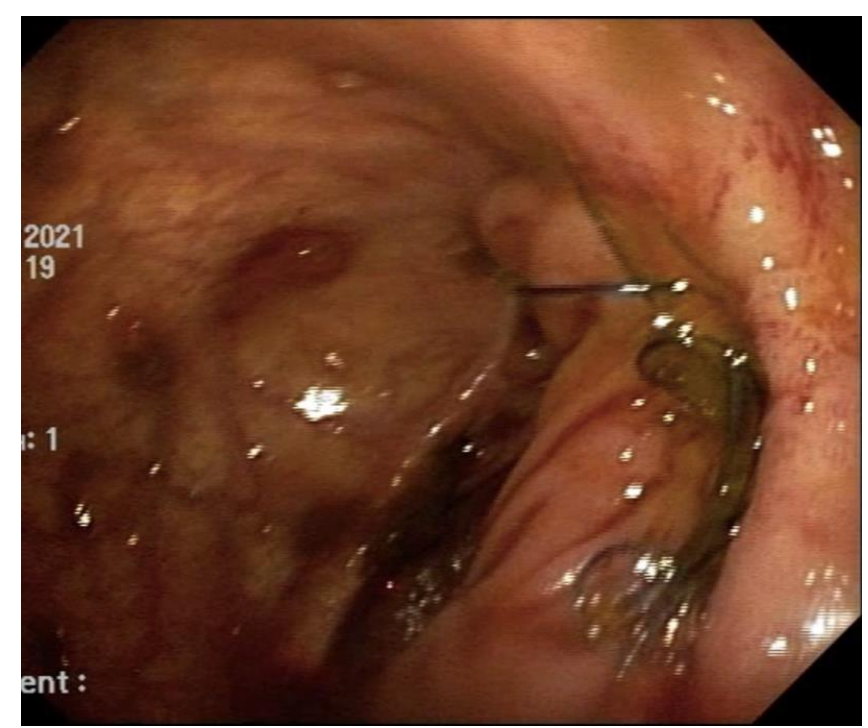

Figure 15: Endoscopic view demonstrating fistula closure in the endoscopic review on the 14th day after VTE. 


\section{Case 6}

A 47-year-old female patient

The patient remained in a underwent total gastrectomy $+\mathrm{D} 2$ lymphadenectomy + esophago-jejunal anastomosis due to the presence of a diffuse type of poorly differentiated gastric adenocarcinoma.

In the postoperative period, the patient developed a high-output enterocutaneous fistula with hydroelectrolotic disturbance, and underwent two surgical re-approaches for fistulorrhaphy and anastomosis reconfection.

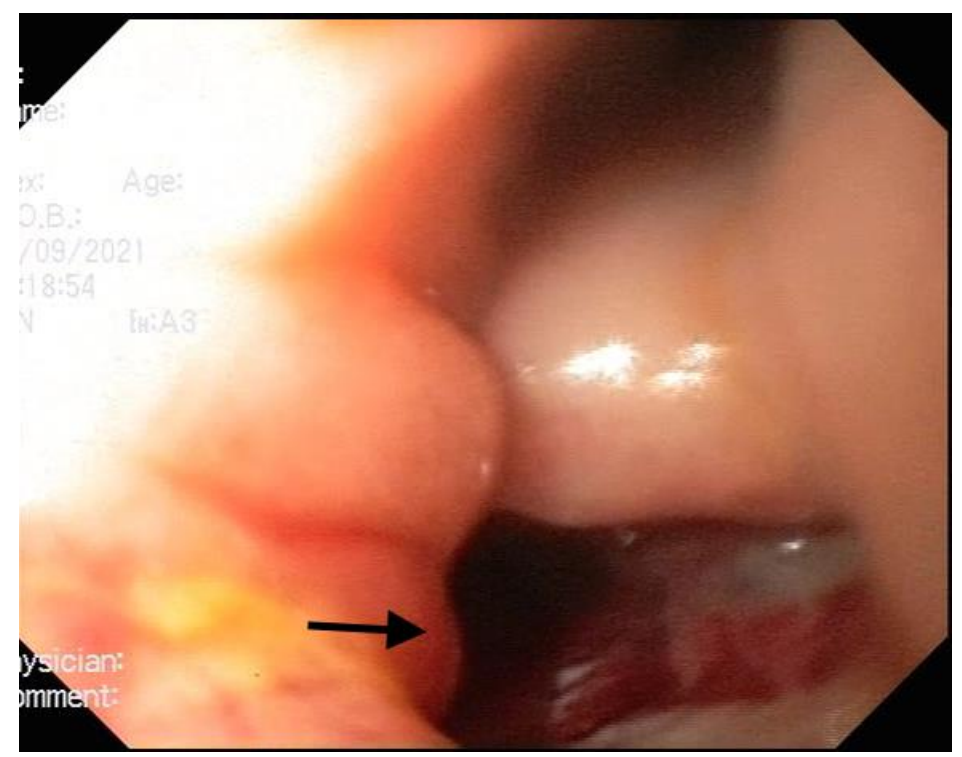

Figure 16: Endoscopic view demonstrating the initial appearance of the fistulous orifice with the presence of necrotic debris (black arrow).

The patient was referred for VTE with placement of a No. 16 nasogastric tube in an intracavitary manner (inside the fistula) (Figure 17). After the 7th and 14th days after VTE, a significant improvement in the local contamination prolonged critical condition, presenting several complications, including persistence of fistula, septic shock, severe malnutrition and encephalopathy.

Upper digestive endoscopy revealed a fistulous orifice at the level of the esophagojejunal anastomosis, approximately $15 \mathrm{~mm}$ in diameter, with necrotic debris and drainage of purulent secretion (Figure 16). 


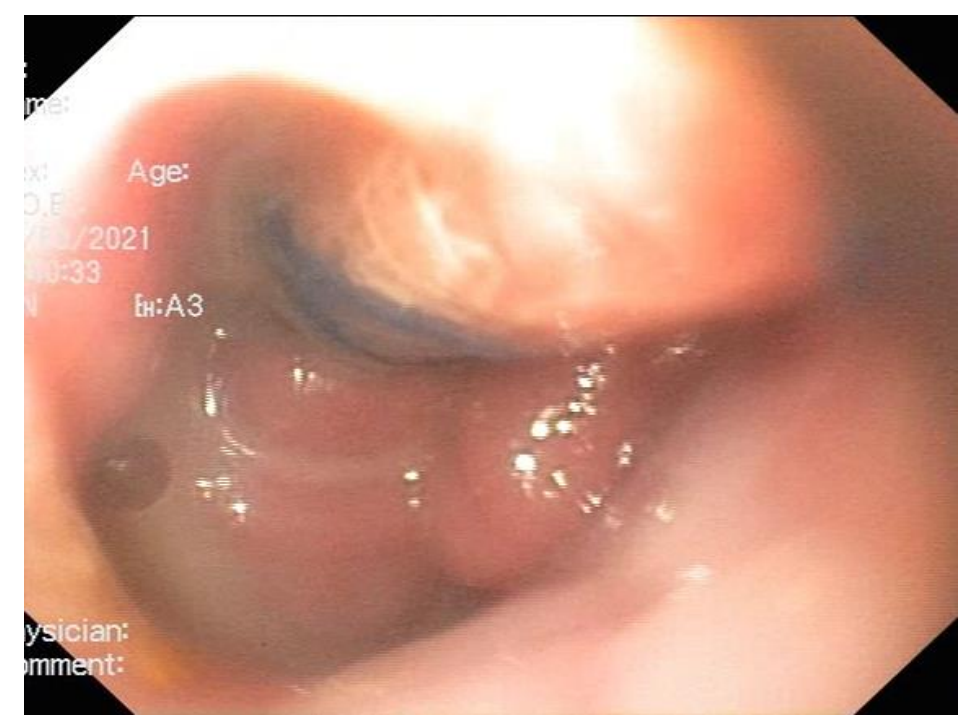

Figure 17: Endoscopic view demonstrating nasogastric tube placement in VTE.
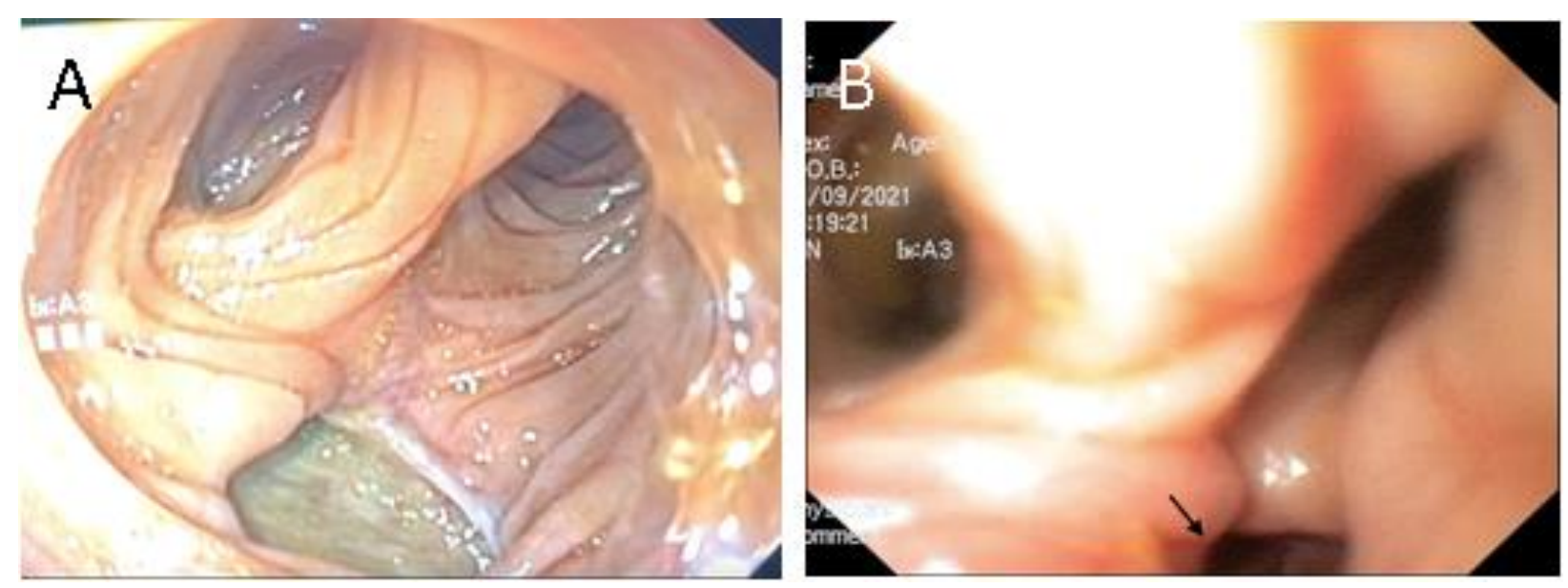

Figure 18: Endoscopic visualization demonstrating the general aspects of the closure of the fistula after the 7 th and 14th days after VTE.

On the 14th day, as the fistula was already presented in an organized way with epithelialized edges, inferring little benefit in the maintenance of vacuum therapy, we chose to conclude it (Figure 19). Palliative care was instituted and the patient was discharged from the hospital, progressing to death after 1 month. 


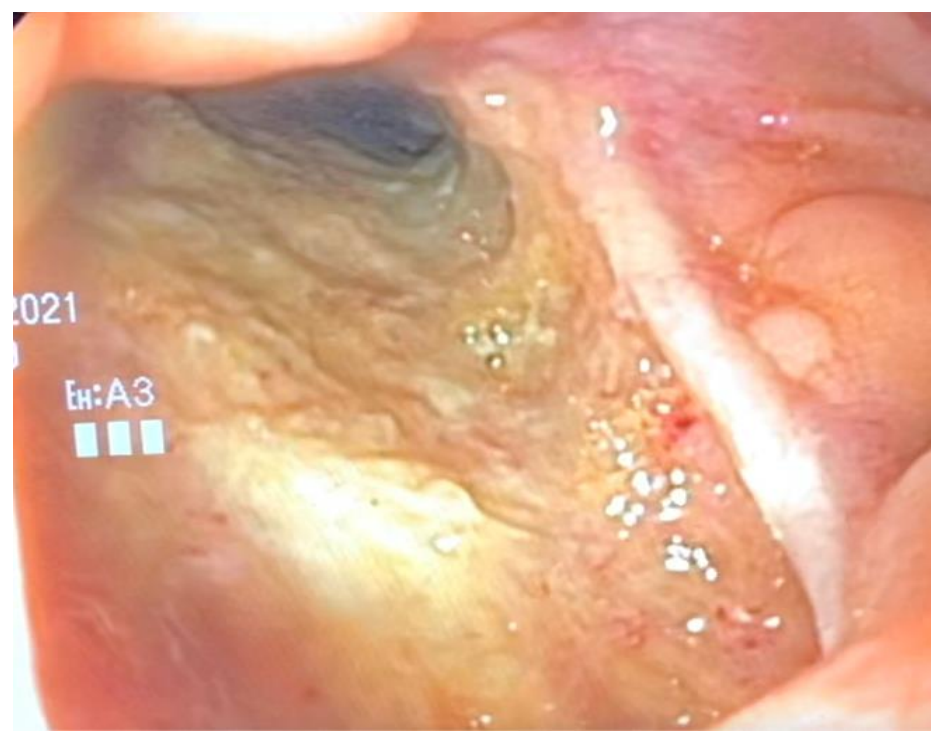

Figure 19: Endoscopic view demonstrating the direct view of the fistulous tract. Epithelized edges are observed, inferring little benefit in maintaining vacuum therapy.

\section{Clinical case descriptions of patients undergoing VTE for the treatment of esophageal fistulas obtained by Integrative Review}

In order to contextualize and discuss the clinical cases presented in the present study, table 1 presents the references of studies of clinical case reports $(n=9)$ that also described cases of patients undergoing VTE for the treatment of esophageal fistulas, characterized by authors, year, diagnosis, outcome and scientific journals used for publication.

Considering that esophageal fistulas are rare, potentially fatal conditions associated with high morbidity and mortality, it appears that there are several studies that describe important clinical findings in patients with a confirmed diagnosis of the presence of esophageal fistulas undergoing VTE treatments.

Recently, Panneerselvam et al (2022) described an important clinical case of a 54-year-old male homeless patient with a history of schizophrenia with symptoms of fever, chills and mental confusion. The patient had a severe infection ( $40 \mathrm{~K} / \mu \mathrm{L}$ leukocytosis) and the presence of air in the hepatic portion of the inferior vena cava (IVC) with a fistulous connection between the distal esophagus and the proximal hepatic IVC associated with a liver abscess diagnosed by computed tomography (CT) [6]. 
Table 1. Presentation of the synthesis of qualitative studies of case reports that described cases of patients undergoing VTE for the treatment of esophageal fistulas.

\begin{tabular}{|c|c|c|c|c|}
\hline № & Author & Year & Diagnosis/Outcome & Journal \\
\hline 1 & $\begin{array}{l}\text { Panneerselvam, et } \\
\text { al. }\end{array}$ & 2022 & $\begin{array}{l}\text { Esophageal perforation by } \\
\text { foreign body }\end{array}$ & $\begin{array}{c}\text { ACG Case Reports } \\
\text { Journal }\end{array}$ \\
\hline 2 & Tuñon et al. & 2021 & $\begin{array}{c}\text { Esophagopleural perforation } \\
\text { in a patient with Boerhaave } \\
\text { Syndrome }\end{array}$ & $\begin{array}{c}\text { BMC } \\
\text { Gastroenterology }\end{array}$ \\
\hline 3 & Loske et al. & 2021 & $\begin{array}{c}\text { Esophagopleural perforation } \\
\text { in a patient with Boerhaave } \\
\text { Syndrome }\end{array}$ & Innov Surg Sci. \\
\hline 4 & Zeyara et al. & 2021 & $\begin{array}{c}\text { Recurrent esophageal fistulas } \\
\text { in a patient with Boerhaave } \\
\text { Syndrome }\end{array}$ & J. Med. Case Rep. \\
\hline 5 & Kim et al. & 2019 & $\begin{array}{c}\text { Esophageal fistula closure in a } \\
\text { patient with Boerhaave } \\
\text { Syndrome after previous } \\
\text { failure of closure }\end{array}$ & $\begin{array}{c}\text { Korean J } \\
\text { Gastroenterology }\end{array}$ \\
\hline 6 & Egin et al. & 2019 & $\begin{array}{c}\text { Closure of esophageal fistulas } \\
\text { in patients with gastric cancer } \\
\text { using a stent }\end{array}$ & $\begin{array}{c}\text { J Coll Physicians Surg } \\
\text { Pak }\end{array}$ \\
\hline 7 & Cwaliński et al. & 2020 & $\begin{array}{l}\text { Closure of esophagogastric } \\
\text { anastomosis dehiscence in } \\
\text { two clinical cases }\end{array}$ & $\begin{array}{l}\text { World J Gastrointest } \\
\text { Endosc }\end{array}$ \\
\hline 8 & Struyve et al. & 2019 & $\begin{array}{c}\text { Closure of esophagogastric } \\
\text { anastomosis leaks }\end{array}$ & $\begin{array}{c}\text { Acta Gastroenterol } \\
\text { Belg. }\end{array}$ \\
\hline 9 & Stašek et al. & 2018 & $\begin{array}{c}\text { Successful closure of grade III } \\
\text { leak after thoracic } \\
\text { esophagectomy }\end{array}$ & Rozhl Chir. \\
\hline
\end{tabular}

It was reported that the patient was urgently referred for an esophagogastroduodenoscopy (EGD) examination, which revealed the presence of a dental floss stick lodged in the distal esophagus, which caused the presence of a large penetrating ulcer at the gastroesophageal junction, and a bottle cap. in the stomach.
From the injection of contrast in the esophagus under fluoroscopy, accumulation of fluid was identified along the superior aspect of the liver, confirming a fistula. Still in the same procedure, the removal of the patient's two foreign bodies was described [6].

The patient underwent treatment with VTE using a vacuum endoscope 
Use of the endoscopic vacuum therapy technique for the treatment of esophageal fistulas

constructed at the bedside using a No.

18 French nasogastric tube and sponge. Under vacuum, the sponge was attached to the end of the nasogastric tube by suture and placed in the distal esophageal lumen at the level of the perforation under negative pressure (175 mm Hg) using a vacuum pump. After four tube changes every 3-7 days, a progressive decrease in the size of the perforation and development of granulation tissue was observed [6].

After 29 days of the procedure, complete healing of the fistula was reported, with no extravasation of contrast in a new EGD procedure, which allowed the patient to return to a solid diet and without associations with new clinical complications [6].

Four recent studies were identified that used VTE treatment for fistula repair in patients with Boerhaave Syndrome (BS) [7-10]. It is noteworthy that BS is an uncommon condition that represents about $15 \%$ of all esophageal perforations, corresponding to a group of patients diagnosed with eosinophilic esophagitis, a chronic inflammatory disease of the esophagus, which has a risk of perforation of about $2 \%$ [11].

On this topic, Tuñon et al. [7] described an unprecedented and rare case of an adult patient diagnosed with eosinophilic esophagitis associated with a complication related to esophageal rupture who developed an esophagealpleural fistula [7].
It was found that, after developing acute retrosternal chest pain that radiated to the upper back, associated with multiple episodes of vomiting (food content) and progressive dyspnea, the patient was admitted to the emergency department with intermittent difficulty swallowing solid foods. associated with fever, infection

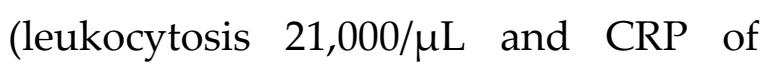
$39.2 \mathrm{mg} / \mathrm{dL}$ ) and sepsis of uncertain origin [7].

The patient underwent chest CT with contrast, showing a clinical picture of pneumomediastinum, cervical emphysema, bilateral pleural effusion, in addition to extraluminal oral contrast surrounding the distal portion of the gastroesophageal junction region accompanied by an air-fluid level indicating collection in the posterior mediastinum region [7].

After an endoscopy examination, the presence of a linear tear of the distal esophagus just above the $Z$ line of approximately $4 \mathrm{~cm}$ with irregular edges was described. It is reported that the success rates of VTE treatment of esophageal fistulas are high; however, it is seen that the treatment of esophagopleural fistulas, especially in patients with BS and eosinophilic esophagitis, is limited [12]. In this premise, the authors described those five days after the patient's admission, it was decided to perform the closure of the fistula area using VTE with the use 
Use of the endoscopic vacuum therapy technique for the treatment of esophageal fistulas

of a sponge allocated to vacuum in the lesion area [7].

It was described that the sponge was cut to $7 \mathrm{~cm}$, adjusted and grasped with an endoscope equipped with a tripod and introduced into the cavity under direct visualization. After placement of the sponge, a vacuum device was connected and adjusted to a continuous subatmospheric pressure of $125 \mathrm{mmHg}$, of moderate intensity. In the second intervention to change the sponge dressing, two OVESCO clips (OTSC®) were placed as a strategy to reduce the size of the laceration and closure of the fistula, reducing the longitudinal size by up to $30 \%$ [7].

Three changes of endoscopic vacuum sponge closure dressings were performed before resolution of the esophageal-pleural fistula was evident. A follow-up endoscopy performed 3 days after removal of the last vacuum closure with a sponge showed the presence of epithelialized esophageal mucosa with granulation tissue [7].

For complete fistula consolidation, it was reported that the patient required four additional changes of endoscopic vacuum sponge-closing dressing, each performed every 72 hours, until the fistulogram showed complete resolution of the esophagopleural fistulous tract, demonstrating efficiency. of the use of VTE for the treatment of esophagealpleural fistulas [7].
Loske et al (2021) described a patient diagnosed with BS who underwent VTE to treat esophageal perforations. A 35-year-old male patient diagnosed with esophageal rupture associated with peritonitis was described. Eleven hours after the esophageal perforation, the patient underwent treatment of the fistula with intraluminal VTE. In addition, the treatment of peritonitis was followed by laparotomy with abdominal lavage [8].

Treatment of VTE was performed with two distinct types followed by two distinct cycles: the first cycle, the first four-day treatment cycle, was performed with open-pore polyurethane foam (DEP) drainage, which was placed in the intraluminal space to cover the perforation defect and emptying the stomach permanently. The second nineday treatment cycle was performed with a thin, double-lumen open-pore drainage (APD) nasogastric tube. For suction, both DEP and DPA were connected with an electronic vacuum pump (-125 mmHg). APD enabled active gastric emptying with simultaneous intestinal feeding through an integrated feeding tube [8].

After 13 days of treatment, the authors showed that VTE was able to achieve complete healing of the defect, without the need for surgical treatment to repair the perforation defect. The patient was discharged 20 days after the initial treatment with a non-irritating 
Use of the endoscopic vacuum therapy technique for the treatment of esophageal fistulas

abdominal wound and closed perforation. Thus, the authors discussed and reaffirmed that, in appropriate cases, VTE is a minimally invasive and organ-preserving procedure for the treatment of spontaneous esophageal rupture, especially in cases of patients with BS [8].

Zeyara et al. [9] described a rare case of recurrence of esophageal fistulas in a patient with BS. The authors described a case of a 60-year-old male patient, alcoholic, with a diagnosis of mild reflux esophagitis and a history of esophageal strain ruptures on two previous occasions associated with BS [9].

The authors report that the first occurrence of fistula was treated by thoracotomy and laparotomy with primary repair and the second time, 5 years after the first occurrence, was treated by transhiatal mediastinal drainage by laparotomy followed by endoscopic stent placement. In the third occurrence of fistula, five years after the second, the patient was affected again with esophageal fistula, however, followed treatment for VTE [9].

After symptoms of chest pain due to repeated episodes of vomiting, after a period of excessive alcohol consumption, the patient was admitted to the emergency department and was referred for CT. CT with oral contrast showed a leak into a small contained paraesophageal / paragastric cavity measuring $2.5 \times 1 \times 5 \mathrm{~cm}$. The patient presented an infectious condition (Leukocytes of $22.8 \times 109 / \mathrm{L}$ and CRP of $9.8 \mathrm{mg} / \mathrm{L}$ ) and underwent UDE, in which the presence of an esophageal fistula was evidenced [9].

Due to the contained nature and small extent of the leak, a minimally invasive approach with VEC alone was attempted. Initially, the sponge was placed extraluminally and then successively retracted into the esophagus. After 10 days of VEC, the defect was no longer visible by endoscopy and a final CT scan showed no signs of leakage and oral intake was carefully resumed. The authors reported that the patient progressed satisfactorily and was discharged after 3 months with confirmation of fistula consolidation by means of a new endoscope examination [9].

Finally, Kim et al. [10] reported the case of a 56-year-old male patient with BS who was successfully treated for VTE after primary closure failure. It was described that the patient had cough and epigastric pain that had started 48 hours before, after several events of vomiting after excessive consumption of alcohol. On clinical admission, the patient presented hypotensive and infectious conditions (leucocytes of $9,740 / \mu \mathrm{L}$ and CRP of $33.6 \mathrm{mg} / \mathrm{dL}$ ). The patient underwent chest CT which revealed esophageal rupture with pneumomediastinum 
Use of the endoscopic vacuum therapy technique for the treatment of esophageal fistulas

associated with concomitant pleural effusion. Esophagogastroscopy showed a longitudinal perforation of $3 \mathrm{~cm}$ above the esophagogastric junction [10].

The patient underwent a surgical procedure by left posterolateral thoracotomy for primary emergency closure of the perforation. However, an abscess in the left thoracic cavity and the presence of coarse pus in the periesophageal space were evidenced. After two attempts to consolidate the perforation, four weeks after the surgical procedure, persistence of the fistula in the paraesophageal cavity was identified. Thus, the authors decided to apply VTE for the purpose of space sterilization and search for complete closure of the esophageal cavity [10.

VTE was reported to be performed using the commercially available CuraVac ${ }^{\circledR}$ system in which a Levine tube (18 Fr.) was inserted through the nose to the mouth followed by preparation of a polyethylene sponge which was cut to fit the perforated cavity and sutured to the end of the Levine tube [10].

Using endoscope forceps, the sponge was grasped and pushed into the drilled cavity by an experienced endoscopist, and a vacuum pump was connected to provide continuous negative pressure $(80-100 \mathrm{mmHg})$. The duration of each TEV lasted 4 days, 3 days, 6 days, 7 days and 7 days in sequential order, respectively [10].
Thirty-seven days after the first VTE, it was described that the patient started to drink water and a light diet. Finally, demonstrating again the efficiency of VTE, it was recorded that the patient was discharged without sequelae and was followed up in the outpatient clinic for 6 months, during which time he maintained a tolerable diet and weight gain, recovering without complications [10].

Egin et al. [13] described a case series of patients who developed esophageal anastomotic fistula after gastric cancer surgery and were treated by two-way VTE with an open abdomen, in addition to endoscopic stenting (EDS). It was highlighted that the gastric tumors of the three patients were limited to the lesser curvature of the gastric body [13].

Patient management was performed by applying the open abdomen (AO) technique with the addition of a two-way VEC to the EDS. It was preferred by surgeons to perform EDS with covered stent during $\mathrm{AO}$ application, and then $\mathrm{AO}$ was performed by closing it with the twoway VEC technique. It was emphasized that the application of bidirectional VEC for the second and third patients was only performed on the eighth and 12th postoperative day, respectively, being postponed due to difficulties in providing covered stents [13]. 
Use of the endoscopic vacuum therapy technique for the treatment of esophageal fistulas

The authors highlighted that in all applications of two-way VEC, intraabdominal fluid culture was performed and the intra-abdominal cavity was flushed with at least $6 \mathrm{~L}$ of saline. All bidirectional VEC applications were carried out with a dedicated VEC management system coupled with an Abthera system that has a central sponge and six additional sponge extensions. It was emphasized that all sponges are covered with protective layers of visceral organs [13].

As a surgical procedure, it was described that one end of the extra sponge extension was placed close to the anastomosis under the left diaphragm and the other end was removed from the left upper quadrant. Five additional sponge extensions were completely soaked in the intraabdominal cavity after washing with at least six liters of warm saline [13].

It was described that an uncovered elliptical sponge was applied above five additional sponge extensions and the back face of the uncovered elliptical sponge was at the level of the fascia and its front face was at the level of the skin. The system was connected with a negative pressure of $75 \mathrm{mmHg}$ to the vacuum device through a collector system [13].

Then, the other end that was removed from the upper left quadrant was covered by the physician with a sterile drape and adhesive and was also connected with a negative pressure of 75 $\mathrm{mmHg}$ to the second vacuum device through a collection system [13].

The follow-up of the esophageal anastomotic fistula was performed by fluoroscopic fistulography. The authors reported that the two-way VEC technique was successful in the three cases described, suggesting that the use of a combination of EDS and bidirectional VEC may provide efficient treatment for severe abdominal sepsis and control of the primary source of infection, in addition to accelerate the development of granulation tissue and rapidly close esophageal fistulas [13].

Cwalinski and colleagues [14] reported that esophagogastric leakage is one of the most serious postoperative complications, emphasizing that partial anastomotic rupture can be successfully treated with an endoscopic vacuumassisted closure, the VEC. On this topic, the authors present two patients with postoperative gastroesophageal leak successfully treated with E-VAC [14].

The first patient, a 53-year-old male, was admitted to the surgical clinic for Siewert type II adenocarcinoma of the gastroesophageal junction. It was described that the patient underwent radical resection of the distal half of the esophagus and upper part of the stomach by means of thoracophrenlaparotomy. It was highlighted that the primary anastomosis of the esophageal remnant with the gastric conduit was 
Use of the endoscopic vacuum therapy technique for the treatment of esophageal fistulas

performed inside the thoracic cavity to restore the continuity of the digestive tract. The postoperative period was complicated with dehiscence of the esophagogastric anastomosis followed by leakage into the mediastinum limited by the gastric conduit, lung and diaphragm, but without entering the pleural cavity [14].

The second patient, a 23-year-old male, was also admitted to the surgical clinic with esophagogastric anastomotic dehiscence 4 days after urgent proximal resection of the stomach due to massive Mallory-Weiss bleeding that did not respond to endoscopic treatment [14]. After imaging tests, after contrast, it was evidenced that the first patient showed a passage of the contrast medium beyond the gastrointestinal tract to the mediastinum, and the endoscopic evaluation revealed a posterior rupture of the esophagogastric anastomosis in $30 \%$ of its circumference [14].

The second patient, after relaparotomy and a two-day stay in the ICU, underwent esophagogastroduodenoscopy which revealed a small dehiscence of less than $10 \%$ of the circumference of the anastomosis in the form of focal necrosis. Computed tomography performed the next day revealed large amounts of gas and fluid in the abdominal cavity [14].

Both patients had postoperative gastroesophageal leak classified as type II and, also in both cases, after the decision to apply VEC to close the fistula, a hand-prepared drain composed of a nasogastric catheter wrapped in polyurethane foam was inserted in the lumen of the gastrointestinal tract and submitted to vacuum in the range of 60 to $100 \mathrm{mmHg}$ [14].

The authors described that in both clinical situations, both patients were successfully treated with VEC in the dehiscent anastomoses with concomitant correction of fluid and electrolyte disturbances and treatment of sepsis with appropriate antibiotics. In both cases, a CT scan was performed at the end of treatment to exclude any presence of fluid reservoir such as abscess, hematoma and intestinal fluid. A control gastroscopy performed in both patients, after three months, revealed complete healing of the anterior anastomotic rupture, reemphasizing the efficiency of VEC in the repair of fistulas [14].

Still on the closure of leaky gastroesophageal anastomoses, Struyve et al. [15] reported the use of VEC in a patient with persistent suture dehiscence after a left thoracophrenolaparotomy with partial esophagectomy and partial gastrectomy with an intrathoracic anastomosis because of a distal esophageal adenocarcinoma [15].

The authors reported a case of a 65-year-old patient who underwent left 
Use of the endoscopic vacuum therapy technique for the treatment of esophageal fistulas

thoracophrene-laparotomy with partial esophagectomy and partial gastrectomy with intrathoracic anastomosis for adenocarcinoma of the distal esophagus. It was described that one month after the surgical procedure, the patient was admitted to the hospital complaining of shortness of breath with observed desaturation and intense cough [15].

Computed tomography of the chest and abdomen showed an esophageal anastomotic fistula due to a suture dehiscence at the level of the esophagogastric anastomosis with a fistula to the right posterior mediastinal space with extension to a collection in the right basal subpleural space. The radiographic esophagogram with iodinated contrast confirmed the presence of an important esophagogastric anastomotic fistula with opacification of a supradiaphragmatic space [15].

The authors described that the patient was treated with surgical correction of the anastomosis, however, there was no successful closure of the fistula. Therefore, this was followed by the establishment of VEC treatment in which two $13 \mathrm{~mm}$ and $15 \mathrm{~mm}$ open pore polyurethane sponges were endoscopically positioned in the wound cavity and continuous aspiration (-75 $\mathrm{mmHg}$ ) was applied through drainage tubes fixed to the sponges [15].

Endoscopic replacement of sponges was performed every 48 to 72 hours where it was possible to reduce the amount and volume of polyurethane sponges [15].

The VEC was stopped at the moment when a significant reduction of the wound cavity and a narrowing of the anastomotic leak was obtained where the anastomotic defect was too small for the placement of a sponge. Successful closure of the anastomotic fistula was achieved after 5 weeks and 15 replacement sessions in total [15].

During the VEC treatment period, nutrition was provided by enteral nutrition with a jejunostomy, which was placed during index surgery. These studies reinforce that the use of VEC as a multidisciplinary endoscopic and surgical approach is a successful therapy for the management of suture dehiscence with esophageal anastomotic leaks after thoracic surgery or esophageal perforations [15].

Finally, we verified the study by Stašek et al. [16] who described that post-esophagectomy leakage occurs in $1-30 \%$ of cases as a significant factor in postoperative morbidity and mortality, accounting for $40 \%$ of postoperative deaths. On this topic, the authors reported a case of a 72-year-old female patient, polymorbid, with Siewert type II adenocarcinoma of the distal esophagus, indicated for resection of the upper stomach and lower thoracic esophagus by laparotomy and thoracotomy with double 
reconstruction. anastomosis stapling [16].

It was described that on the 12th postoperative day, a 3rd degree leak was confirmed on CT with propagation to the right pleural cavity, with endoscopy showing a defect affecting $30 \%$ of the cavity circumference of $7 \times 3 \times 3$ $\mathrm{cm}$. Due to the morphology of the leak, the use of VEC was indicated, comprising 12 sessions with intervals of 3 to 4 days for a total duration of 40 days with 5 extraluminal and 7 intraluminal applications and negative pressure of 100-125 mmHg [16].

It was verified that the patient's clinical condition was complicated by global respiratory failure due to severe pneumonia, and artificial ventilation was ended on the 58th postoperative day. The patient was discharged to a rehabilitation unit on the 90th postoperative day. Follow-up 3 months after discharge confirmed the patient's satisfactory performance results with full recovery from the esophageal injury [16].

Thus, Stašek et al. [16] described that the use of VEC as a therapy for complications of intrathoracic anastomoses after esophagectomy has shown a tendency to reduce invasiveness and greater implementation of endoscopic methods, thus being a safe and highly effective therapeutic option even for extensive anastomotic defects [16].

\section{Conclusion}

Based on the data obtained in this study, it was possible to conclude that there is a significant number of case reports that demonstrate the impact of the occurrence of esophageal fistulas treated with endoscopic vacuum therapy associated with different clinical occurrences, such as Boerhaave Syndrome, carcinomas and dehiscence of esophagogastric anastomosis.

It is noteworthy that the main clinical diagnoses reported in the present study that led to the occurrence of esophageal fistulas were mainly associated with advanced stages of digestive system neoplasms, such as esophageal squamous cell carcinoma and advanced stomach adenocarcinoma, similar to the cases clinicians presented. It should be noted that an interesting case of fistulas caused by esophageal ulcers due to the presence of a foreign body was presented, which, to our knowledge, is considered a case rarely described in the literature. Regardless of the diagnosis that caused the fistula, the clinical reports presented here reinforce the importance and efficiency of VTEmediated treatment.

Finally, there is a need for continuous development of new clinical studies that seek to improve and validate the use of VTE for the safe and effective treatment of esophageal fistulas, emphasizing that, based on the findings presented in this study, the 
treatment with VTE was able to maximize the therapeutic response, bringing greater and better clinical satisfaction to the patient.

\section{References}

[1] Chirica M, Champault A, Dray X, Sulpice L, Munoz-Bongrand N, Sarfati E, Cattan P. Esophageal perforations. J Visc Surg. 2010 Jun;147(3):e117-28. doi: 10.1016/j.jviscsurg.2010.08.003.

[2] Vidarsdottir H, Blondal S, Alfredsson $\mathrm{H}$, Geirsson A, Gudbjartsson T. Oesophageal perforations in Iceland: a whole population study on incidence, aetiology and surgical outcome. Thorac Cardiovasc Surg. 2010 Dec;58(8):476-80. doi: 10.1055/s-0030-1250347.

[3] Szymanski K, Ontiveros E, Burdick JS, Davis D, Leeds SG. Endolumenal Vacuum Therapy and

Fistulojejunostomy in the Management of Sleeve Gastrectomy Staple Line Leaks. Case Rep Surg. 2018 Mar 4;2018:2494069. doi: $10.1155 / 2018 / 2494069$.

[4] Leeds SG, Mencio M, Ontiveros E, Ward MA. Endoluminal Vacuum Therapy: How I Do It. J Gastrointest Surg. 2019 May;23(5):1037-1043. doi: 10.1007/s11605-018-04082-z.

[5] Kuehn F, Loske G, Schiffmann L, Gock M, Klar E. Endoscopic vacuum therapy for various defects of the upper gastrointestinal tract. Surg Endosc. 2017
Sep;31(9):3449-3458. doi: 10.1007/s00464016-5404-x.

[6] Panneerselvam K, Samuel R, Sealock RJ. Esophageal Perforation Successfully Treated With EVT. ACG Case Rep J. 2022 Jan 12;9(1):e00711. doi: 10.14309/crj.0000000000000711.

[7] Tuñon C, De Lucas J, Cubilla J, Andrade R, Aguirre M, Zúñiga Cisneros J. Endoluminal vacuum therapy in the management of an esophago-pleural fistula as a complication of Boerhaave syndrome in a patient with eosinophilic esophagitis. BMC Gastroenterol. 2021 Dec 20;21(1):484. doi: 10.1186/s12876021-02058-z.

[8] Loske G, Albers K, Mueller CT. Endoscopic negative pressure therapy (ENPT) of a spontaneous oesophageal rupture (Boerhaave's syndrome) with peritonitis - a new treatment option. Innov Surg Sci. 2021 Apr 6;6(2):81-86. doi: 10.1515/iss-2020-0043.

[9] Zeyara A, Jeremiasen M, Åkesson O, Falkenback D, Hermansson $M$, Johansson J. Third time recurrent Boerhaave's syndrome: a case report. J Med Case Rep. 2021 May 2;15(1):223. doi: 10.1186/s13256-021-02779-5.

[10] Kim YE, Do YW, Cho JY, Kim ES, Lee DH. Successful Treatment Using Endoluminal Vacuum Therapy after Failure of Primary Closure in Boerhaave Syndrome. Korean J Gastroenterol. 2019 


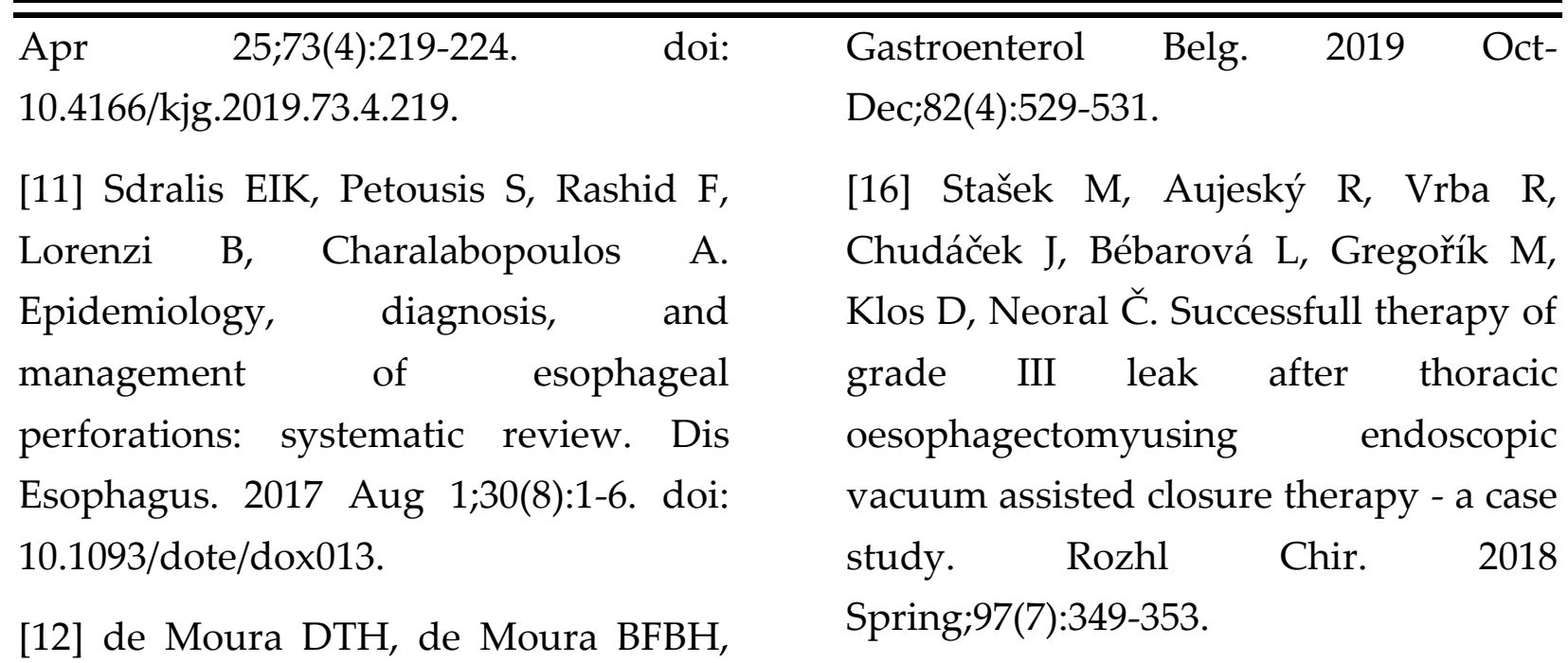
Manfredi MA, Hathorn KE, Bazarbashi AN, Ribeiro IB, de Moura EGH, Thompson CC. Role of endoscopic vacuum therapy in the management of gastrointestinal transmural defects. World J Gastrointest Endosc. 2019 May 16;11(5):329-344.

[13] Egin S, Hot S. Improvement of Esophageal Anastomotic Leak by Vacuum-assisted Closure in Three Cases with Gastric Cancer. J Coll Physicians Surg Pak. 2019 Dec;29(12):S98-S100. doi: 10.29271/jcpsp.2019.12.S98.

[14] Cwaliński J, Hermann J, Kasprzyk M, Banasiewicz T. Endoscopic vacuum assisted closure of esophagogastric anastomosis dehiscence: A case report. World J Gastrointest Endosc. 2020 Jan 16;12(1):42-48. doi: 10.4253/wjge.v12.i1.42.

[15] Struyve M, De Vloo C, Van Veer H, Depypere L, Nafteux P, Roelandt P. Endoscopic vacuum-assisted closure therapy for the treatment of oesophageal anastomotic leaks. Acta 